Chapter 4

\title{
The Molecular Basis of ABA-Mediated Plant Response to Drought
}

\author{
Agata Daszkowska-Golec and Iwona Szarejko \\ Additional information is available at the end of the chapter \\ http://dx.doi.org/10.5772/53128
}

\section{Introduction}

'Drought stress is as complicated and difficult to plant biology as cancer is to mammalian biology' said Jian-Kang Zhu, a molecular geneticist at the University of California, Riverside. The capacity of a plant to turn on or turn off a series of genes that further alter plant physiology and morphology allows a plant to tolerate, escape or avoid drought stress. Many countries around the world experience drought stress in different ways but it always leads to a decreased annual yield of crops. Deciphering the basis of the molecular response to stress and the mechanism for the adaptation and acquisition of tolerance can facilitate the creation of cultivars with increased drought tolerance. Drought response is a complex mechanism that has been investigated using a broad spectrum of 'omics' techniques, such as molecular genetics, functional genomics, transcriptomics, proteomics and metabolomics combined with advanced phenotyping techniques. The response of plants to dehydration stress has been extensively studied in a wide range of species with particular emphasis on model plants such as Arabidopsis. Taking advantage of the knowledge already obtained from Arabidopsis and other model species, it is possible to gain insight into the stress response in crops such as barley or wheat.

The best known trigger of the cascade of drought signaling is abscisic acid (ABA). Knowledge about the complexity of ABA signaling in regards to stress response is still full of gaps but the recent identification of ABA receptors and the key factors of the first step of ABA signal transduction in Arabidopsis provided an important insight into this mechanism ([1-4]. The actions of the other ABA signaling components, such as phosphatases, kinases, transcription factors and their roles in abiotic stress response during different developmental stages is also documented in crops [5]. Under drought conditions, ABA induces the expression of many genes whose products are involved in the response 
to drought, among which are positive and negative regulators of ABA signaling, transcription factors and genes encode enzymes that are involved in the synthesis of osmoprotectants. It is important to mention that $\mathrm{ABA}$ is not the only phytohormone involved in stress response. There is much evidence of cross-talk between ABA and other phytohormones, such as jasmonates and ethylene [6].

Recent advances in functional genomics have revealed the importance of posttranscriptional regulation of gene expression performed by microRNA. Deep sequencing methods have enabled the identification of the miRNA involved in drought response in barley and rice. Further analysis also showed their potential roles in stress signaling by identifying their targets [7-8].

The molecular basis of drought response and the interaction between genes and proteins involved in this mechanism can be studied using of advanced molecular techniques only when a good drought assay that mimics natural drought conditions can be applied in the laboratory. Many protocols for drought assays have been developed that can be implemented in the study of different species ranging from Arabidopsis to crops. Another important issue is the method of phenotyping and the spectrum of physiological parameters that are measured [9]. The techniques used most often are: chlorophyll fluorescence, stomatal conductance and relative water content (RWC) [10-12]. Combining these molecular techniques with advanced methods of phenotyping would enable drought tolerant forms to be produced. This would contribute to beginning the Blue Revolution advocated by Kofi Annan in his April 2000 Millennium Address: “We need a Blue Revolution in agriculture that focuses on increasing productivity per unit of water - more crop per drop". This chapter reviews the newest aspects of the molecular and physiological mechanisms of drought stress response in crops.

\section{Abscisic acid - The best known stress messenger}

Since its isolation from cotton in the 1960s [13], the role of abscisic acid (ABA) in plant development and in the response of plants to environmental signals has been extensively studied. Analysis of Arabidopsis under salt and drought stress has revealed the important role ABA plays in response to these stresses [14-16]. Endogenous ABA concentrations increase under drought stress due to induction of ABA biosynthesis genes [14]. The increase in ABA reprograms the gene expression pattern to regulate water relations through adjustment of cellular osmotic pressure, the closure of stomata, a reduced leaf canopy, deeper root growth and changes in root system architecture [17-19].

Biosynthesis of ABA has been relatively well characterized in Arabidopsis and some data is available for other species, such as maize, tomato, potato and barley [20-24]. Knowledge about ABA biosynthesis derived from studies in Arabidopsis is highly applicable to other plant species, because the pathway and the respective genes are conserved in angiosperms. ABA is synthesized through the cleavage of a C40 carotenoid precursor, followed by a twostep conversion of the intermediate xanthoxin to ABA via ABA-aldehyde [25-27]. The path- 
way begins with isopentyl pyrophosphate (IPP) which is the biological isoprene unit and the precursor of all terpenoids, as well as many plant hormones. The next step is the epoxidation of zeaxanthin and antheraxanthin to violaxanthin which is catalyzed by zeaxanthin epoxidase (ZEP), which was first identified in tobacco [28]. After a series of violaxanthin modifications which are controlled by the enzyme ABA4, violaxanthin is converted into 9cis-epoxycarotenoid [29]. Oxidative cleavage of the major epoxycarotenoid 9-cis-neoxanthin by the 9-cis-epoxycarotenoid dioxygenase (NCED) yields a C15 intermediate - xanthoxin [30]. This step is the last one that occurs in the plastid. Xanthoxin is exported to the cytoplasm where two-step reaction via ABA-aldehyde takes place. The first step is catalyzed by a short-chain alcohol dehydrogenase/reductase (SDR) that is encoded by the AtABA2 (ABA deficient 2) gene [31-33] and generates $A B A$ aldehyde. Then the ABA aldehyde oxidase (AAO) with the molybdenum cofactor $(\mathrm{MoCo})$ catalyzes the last step in the biosynthesis pathway - the conversion of ABA-aldehyde into ABA [34].

Drought stress has been shown to up-regulate NCED3 expression in Arabidopsis [14], maize [21], tomato [35], bean [15] and avocado [36]. A significant increase in NCED transcript levels can be detected within 15 to 30 min after leaf detachment or dehydration treatment [15; 37], indicating activation of NCED genes can be fairly quick. Cheng et al. [32] reported that the AtNCED3 gene (and AtZEP (Zeaxanthin Epoxidase) and AtAAO3 (ABA aldehyde oxidase)) could be induced in the Landsberg erecta background by ABA and studies in rice showed that OsNCED3 expression was induced by dehydration [38]. Immunohistochemical analysis, using antibodies raised against AtNCED3, revealed that the protein is accumulated in the leaf vascular parenchyma cells in response to drought stress. it was not detected under nonstressed conditions. These data indicate that the drought induction of ABA biosynthesis occurs primarily in vascular tissues and that vascular-derived ABA might trigger stomatal closure via transport to guard cells [39]. AtNCED3 expression is up-regulated by drought conditions across observed species and decreases after rehydration. At the same time, the expression level of AtCYP707A1, 2, 3 and 4 (CYTOCHROME P450, FAMILY 707, SUBFAMILY A, POLYPEPTIDE 1, 2, 3, 4) were induced by rehydration [40-41]. These genes, which encode the hydroxylases that are responsible mostly for ABA catabolism, were identified in Arabidopsis, rice [42], barley [43], wheat [44] and soybean [45]. OsABA8ox1 (ABA-8-hydroxylase 1) expression is induced dramatically by rehydration, which can lead to a decrease in the ABA content in rice leaves [42].

The balance between active and inactive ABA is very important for plant stress response and is achieved not only by biosynthesis and catabolism reactions, but also by conjugation and deconjugation. ABA can be inactivated at the C-1 hydroxyl group by different chemical compounds that form various conjugates and accumulate in vacuoles or in the apoplastic space [46]. The most widespread conjugate is ABA glucosyl ester (ABA-GE) which is catalyzed by ABA glucosyltransferase [47-48]. Lee et al [49] identified the AtBG1 (BETA-1,3-GLUCANASE 1) protein which is responsible for the release of ABA from ABA-GE. Their findings showed that ABA de-conjugation plays a significant role in providing an ABA pool for plants that allows them to adjust to changing physiological and environmental conditions. 
The ability of ABA to move long distances allows it to serve as a critical stress messenger. ABA transport was long assumed to be a diffusive process, mainly due to the ability of ABA to diffuse passively across biological membranes when it is in a protonated state [50]. The last step of ABA biosynthesis occurs in the cytosol where $\mathrm{pH}$ is estimated to be 7.2-7.4. In the apoplastic space, where ABA is meant to be transported before reaching the target cell, the $\mathrm{pH}$ is estimated to be around 5.0-6.0. Although ABA can be passively transported from a low $\mathrm{pH}$ to a higher one with a $\mathrm{pH}$ gradient, there is a need for the transporter to allow $\mathrm{ABA}$ to get into the target cell and to be exported from the cell to the apoplast. During stress response, the strong alkalization of apoplastic $\mathrm{pH}$ would slow ABA diffusive transport from the apoplastic space to the target cells. Because of the predominance of a non-protonated $\mathrm{ABA}$ state, there is a need for the existence of ABA transporters. The identification of $\mathrm{ABA}$ transporters in target cell membranes, such as the cell membranes of guard cells, has resolved the problem of how ABA gets into the cells when passive transport is decreased under stress conditions. One of the identified ABA importers is ABCG40 (ARABIDOPSIS THALIANA ATP-BINDING CASSETTE G40) described by Kang et al [51]. The expression of $A B C G 40$ is not tissue specific and its product localizes in cell membranes [51]. Kuromori et al [52] identified another ABA importer - ABCG22 (ARABIDOPSIS THALIANA ATPBINDING CASSETTE G22). The gene encoding this transporter is mainly expressed in guard cells. Also, the expulsion of ABA into the intercellular space is mediated by transporters such as ABCG25 (ARABIDOPSIS THALIANA ATP-BINDING CASSETTE G25). ABCG25 is expressed mainly in vacuolar tissue, where ABA is synthesized [53].

A breakthrough in understanding ABA signaling occurred recently when several groups identified key ABA receptors. Chemical genetics emerged as the solution for the problem of the identification of receptor. Pyrabactin (4-bromo-N-[pyridine-2-yl methyl]naphthalene-1sulfonamide) is a synthetic compound that partially mimics the inhibitory effect of ABA during seed germination and seedling development. Using a series of pyrabactin-resistant mutants and the map-based cloning approach, several genes encoding ABA-binding proteins, among them PYR1 (PYRABACTIN-RESISTANCE 1) have been identified [3]. PYR1 is one of the 14 homologs (PYL - PYRABACTIN RESISTANCE LIKE) present in the Arabidopsis genome [1-4]. After receiving ABA from ABC transporters, the PYR/PYL/RCAR-ABA (PYRABACTIN-RESISTANCE 1/ PYRABACTIN RESISTANCE LIKE/ REGULATORY COMPONENT OF ABA RECEPTOR) complex perceives ABA intracellularly and forms ternary complexes inhibiting clade A of PP2Cs (PROTEIN PHOSPHATASE 2C), the negative regulators of ABA signaling, such as ABI1 (ABA INSENSITIVE 1), ABI2 (ABA INSENSITIVE 2), HAB1 (HYPERSENSITIVE TO ABA1) [1-2; Table 1].

This allows the activation of down-stream targets of PP2Cs - the Sucrose nonfermenting 1related subfamily 2 protein kinases (SnRK2), such as SnRK2.2/D, SnRK2.3/E and SnRK2.6/ OST1/E which are the key players in the regulation of ABA signaling [54-57; Figure 1].

The last enzyme, OST1 (OPEN STOMATA1), displays dominant kinase activity during drought stress response when the ABA signal is relayed to the guard cells. Mutants in OST1 showed a wilty phenotype under water deficit conditions [58]. Mutants for the other two ABA-activated kinases, $S n R K 2.2$ and $S n R K 2.3$, did not show a drought-sensitive phenotype 
[59]. The triple mutant snrk2.2/d snrk2.3/I snrk2.6/e displayed an extremely sensitive phenotype under water deficit conditions. Transcriptomic studies of the triple mutant showed a down-regulation of genes encoding PP2Cs, which suggested a feedback loop in the transcription regulation of PP2Cs by SnRKs [54].

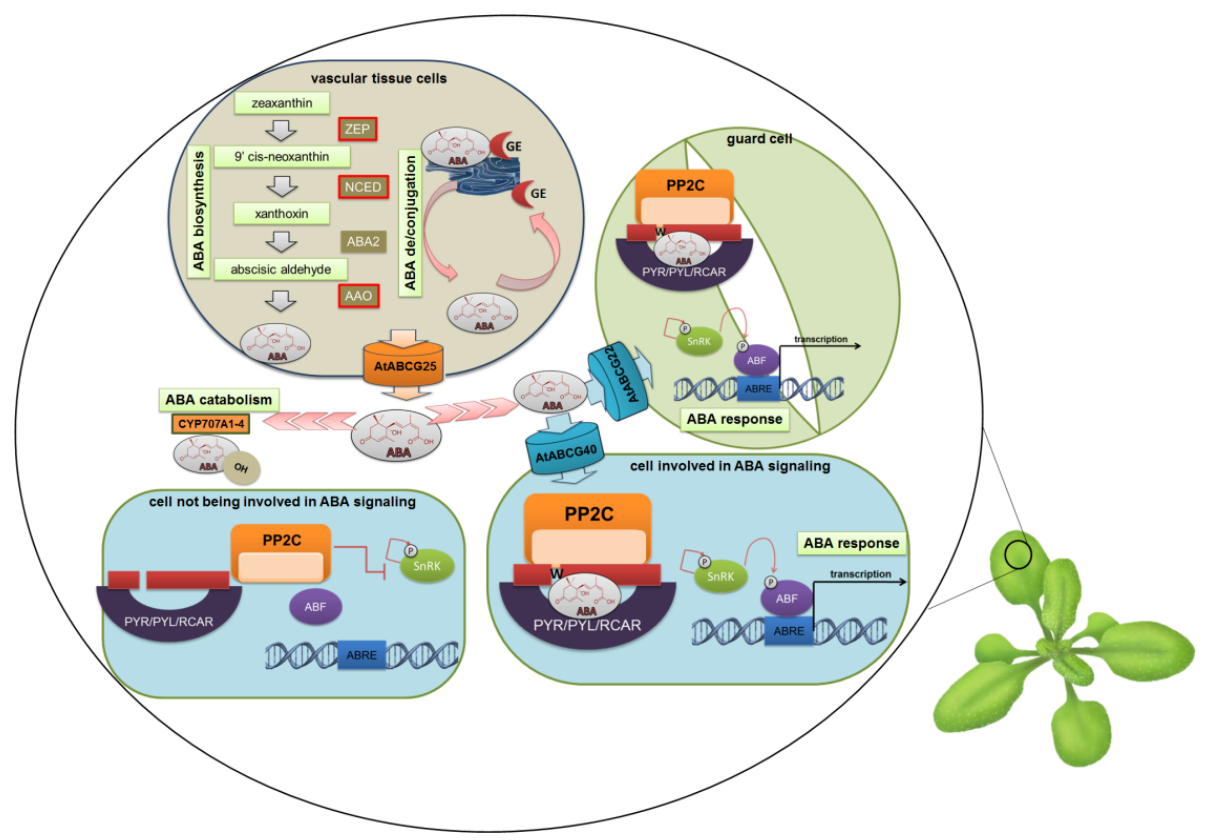

Figure 1. ABA synthesis, catabolism, conjugation and response in a scheme.

One of the earliest plant responses to water deficit condition, and one regulated mainly in an ABA-dependent manner, is the closure of stomata. The closing or opening of the pore is a result of the osmotic shrinking or swelling, of the two surrounding stoma guard cells. ABA acts directly on the guard cells and induces stomata closure via an efflux of potassium and anions from the guard cells [60]. ABA regulation of the membrane ion channels is mediated by increased cytosolic $\mathrm{Ca}^{2+}$ resulting from the release of $\mathrm{Ca}^{2+}$ from intracellular stores and a $\mathrm{Ca}^{2+}$ influx from the extracellular space. It is worth noting that a number of mutations that affect ABA signaling in regards to stomatal action during drought have been characterized. Dominant mutations have been described in genes that encode type-2C phosphatases - ABI1 (ABA INSENSITIVE 1) and ABI2 (ABA INSENSITIVE 2) [61-62], whereas recessive mutations that lead to supersensitivity to ABA in regards to stomata closure are found in genes that encode farnesyltransferase $\beta$-subunit - ERA1 (ENHANCED RESPONSIVE TO ABA1) [63-64], a larger subunit of cap binding complex CBP80 (CAP BINDING PROTEIN 80) [65] and the Sm-like snRNP protein SAD1 (SUPERSENSITIVE TO ABA AND DROUGHT 1) [66]. 


\begin{tabular}{|c|c|c|}
\hline RCAR & PYR/PYL & PP2C interactors \\
\hline RCAR1 & PYL9 & $\mathrm{ABI} 1^{[1],[4]}, \mathrm{ABI} 2^{[1]}, \mathrm{HAB} 1^{[1]}$ \\
\hline RCAR2 & PYL7 & $A B \mid 1^{[4]}$ \\
\hline RCAR3 & PYL8 & $\mathrm{HAB} 1^{[3],} \mathrm{ABI} 1^{[4]}$ \\
\hline RCAR4 & PYL10 & $\mathrm{AB} \mid 1^{[4]}$ \\
\hline RCAR5 & PYL11 & $\mathrm{HAB} 1^{[3]}, \mathrm{ABI} 1^{[4]}$ \\
\hline RCAR6 & PYL12 & $\mathrm{PP} 2 \mathrm{CA} / \mathrm{AHG}^{[2]}$ \\
\hline RCAR7 & PYL13 & \\
\hline RCAR8 & PYL5 & $\mathrm{HAB} 1^{[3]}, \mathrm{ABI} 1^{[4]}$ \\
\hline RCAR9 & PYL6 & $\mathrm{ABI} 1^{[1],[4]}, \mathrm{ABI} 2^{[1],} \mathrm{HAB} 1^{[1]}$ \\
\hline RCAR10 & PYL4 & $\mathrm{HAB} 1^{[2]}, \mathrm{ABI} 1^{[4]}$ \\
\hline RCAR11 & PYR1 & $\mathrm{HAB} 1^{[2]}, \mathrm{ABI} 1^{[4]}$ \\
\hline RCAR12 & PYL1 & $\mathrm{HAB} 1^{[2]}, \mathrm{ABI} 1^{[4]}$ \\
\hline RCAR13 & PYL3 & $\mathrm{HAB} 1^{[2]}$ \\
\hline RCAR14 & PYL2 & $\mathrm{HAB} 1^{[2]}$ \\
\hline
\end{tabular}

Table 1. The nomenclature of the different soluble receptors and their PP2Cs interactors

\section{Abscisic acid is not the only phytohormone in stress response}

The effectiveness of ABA is regulated not only by the length of a drought or the previous stress history of a given plant, but also by other phytohormones such as jasmonates, cytokinins and ethylene. The role of jasmonic acid (JA) has been well established in regards to plant development and defense responses [67]. Recently, it was also shown that jasmonic acid (JA) and methyl jasmonate (MeJA) are involved in the regulation of drought response. When JA or MeJA are applied exogenously to plants they are converted into a biologically active form (+)-7-iso-Jasmonoyl-L-isoleucine (JA-Ile). JA-Ile is then bound by the receptor SCFCOI complex that contains the CORONATINE INSENSITIVE1 (COI1) F-box protein [68-69]. This interaction leads to the degradation of the repressor protein - JAZ (Jasmonate ZIM-domain) by the 26S proteasome, it allows MYC2 (MYC DOMAIN TRANSCRIPTION FACTOR 2) activation of a distinct JA response genes [70-72]. In the absence of JA, JAZ inhibits MYC2 in order to activate the transcription of JA-inducible genes. It was showed that MYC2 is up-regulated not only by JA, but also by ABA and drought. The described interaction between the protein specific to jasmonates - JAZ and both jasmonates and also ABA and drought-inducible MYC2 suggest the important regulatory role of JA in an ABA-dependent response to drought. A similar mechanism has been described in rice [73]. It was shown that, in addition to ABA, jasmonates also trigger stomatal closure in response to drought in 
various species, including Arabidopsis and barley [74-76]. Low endogenous ABA content in the ABA-deficient mutant aba2 impairs MeJA (methyl-jasmonate)-stimulated $\mathrm{Ca}^{2+}$ elevation, which is, in turn, important metal closure. Furthermore, MeJA stimulates the expression of the ABA biosynthetic gene, NCED3. MeJA signaling in guard cells requires the presence of endogenous ABA [77]. Another example of cross talk between ABA and jasmonates during stress response is the up-regulation by JA of AtPYL4 (PYRABACTINE LIKE 4), AtPYL5 (PYRABACTINE LIKE 5) and AtPYL6 (PYRABACTINE LIKE 6), which are members of the $P Y R / P Y L / R C A R$ ABA receptor family [78]. These studies showed the importance and conservation across the species of the role of JA in ABA-dependent response to drought.

Cytokinins (CKs) are another group of hormones involved in stress responses [79-80]. Cytokinins regulate cell proliferation and differentiation [81]. Abiotic stresses, such as drought, decrease the biosynthesis and transport of CKs from roots to shoots [82]. An increased concentration of $\mathrm{CKs}$ in xylem has been shown to decrease stomatal sensitivity to ABA [83]. The same effect was observed when exogenous CKs were applied [84-85]. When a plant encounters mild drought conditions, it is not necessary to close the stomata and further limit its photosynthetic rate. Since the decline in CK content increases the stomatal sensitivity to ABA, avoidance of this phenomenon might help in obtaining a better yield from plants that experience mild drought. CK up-regulation can be achieved by reduced expression of a gene that encodes cytokinin oxidase, an enzyme that degrades CKs. In addition to maintaining a better photosynthetic rate, increased levels of CKs lead to enhanced activity of the cell-cycle genes, and the consequent, increase in cell number may result in improved grain filling [86]. The process of grain filling is actually an increase in cell number and cell filling in the endosperm [87]. There is a generally positive relationship between endosperm cell number and grain weight in wheat [88], barley [89], maize [90] and rice [91]. Thus, endosperm cell number is one important factor determining grain weight [87]. Taking into account that endosperm cell number in cereal crops is established during an early phase of development, it is assumed that this step can be regulated by cytokinins [87]. Another manipulation of the CK level in plant tissues was achieved by seed inoculation with CK-producing bacteria, gradually releasing CKs within the physiological concentration range [92]. Wheat plants in which seeds were treated with such bacteria and grown under mild drought condition gave a 30-60\% higher yield than non-treated controls. Since a high level of CKs improves grain quality and photosynthesis rate, and a high level of ABA increases root extension rate, osmoprotectant activity, and solute biosynthesis, another aim of breeders is to obtain a high content of both ABA and CKs under mild drought conditions Wilkinson et al. [6].

Ethylene, a gaseous plant hormone that inhibits root growth and development, is involved in stress-induced leaf senescence and can contribute to reducing the rate of photosynthesis [93-95]. ABA can modulate the influence of ethylene on stomatal conductance. Contradictory results have been published regarding the role of ethylene in stomatal action. Desikan et al. [96] showed that ethylene induces stomatal closure, whereas Tanaka et al. [97] and Wilkinson and Davies [98] proved that ethylene can antagonize ABA action in the stomata. This 
is probably due to the fact that the concentration of neither hormone is important for the final effect but rather the ratio of ABA to ethylene [99; 18].

\section{With a little help from arabidopsis - Transferring knowledge from weeds to crops}

A small genome, short life cycle, small stature, prolific seed production, ease of transformation, a completely sequenced genome, a near saturation insertion mutant collection, a genome array that contains the entire transcriptome - these are the major advantages of using the model plant Arabidopsis in studies on the molecular basis of responses to environmental stresses including drought. The identification of stress-related genes, their functions and the pathways they are involved in, has been facilitated by an increasing number of molecular tools, genetic resources and the large number of web-based databases available for Arabidopsis (Table 2).

Genomic resources and results obtained of Arabidopsis provide a resource for exploitation in crops. Using sequence homology, EST (Expressed Sequence Tag) libraries, and the fulllength cDNA repositories available for crop species, there is a possibility of a simple transfer of data revealed in Arabidopsis to identify a gene of interest in a crop species (Figure 2).

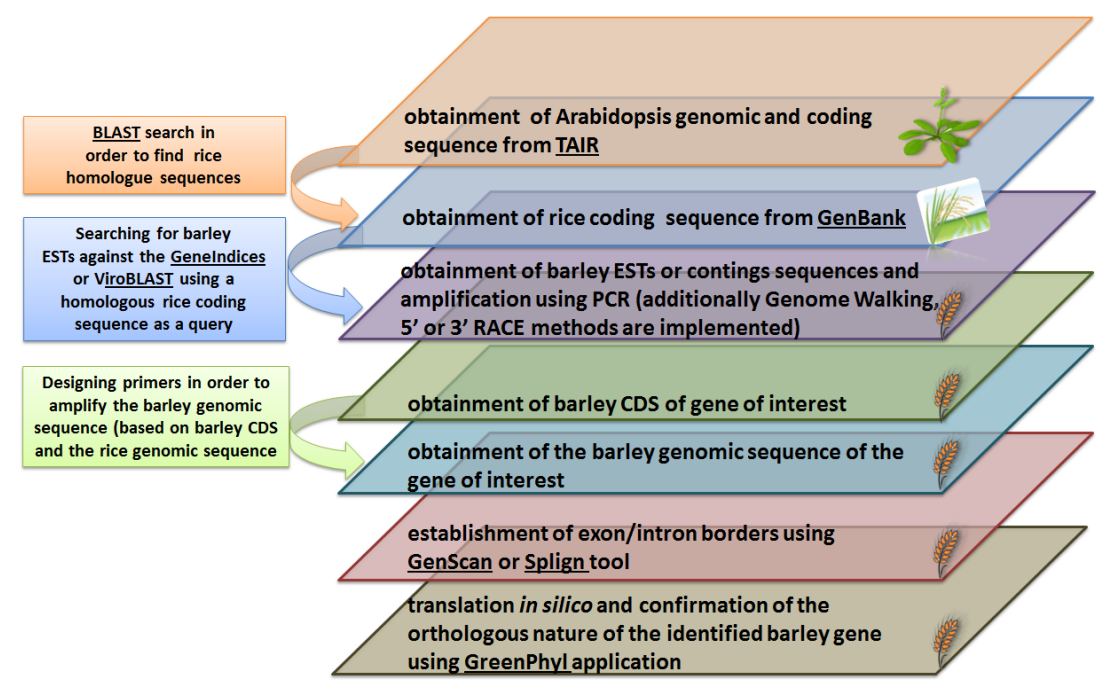

Figure 2. The pipeline of identification of barley homologous gene based on Arabidopsis and rice information. GenBank: http://www.ncbi.nlm.nih.gov/genbank/; TAIR: www.arabidopsis.org; BLAST: http://blast.ncbi.nlm.nih.gov/ Blast.cgi; Genelndices: http://compbio.dfci.harvard.edu/cgi-bin/tgi/gimain.pl?gudb=barley; GenScan: http:// genes.mit.edu/GENSCAN.html; Splign: http://www.ncbi.nlm.nih.gov/sutils/splign/splign.cgi; GreenPhyl: http://greenphyl.cirad.fr/v2/cgi-bin/index.cgi. 


\begin{tabular}{|c|c|c|}
\hline Type & Resource/ database & URL \\
\hline \multirow{10}{*}{$\begin{array}{l}\text { Integrative } \\
\text { databases }\end{array}$} & TAIR & http://www.arabidopsis.org/ \\
\hline & MIPS & http://mips.helholtz-muenchen.de \\
\hline & PlantGDB & http://www.plantgdb.org/ \\
\hline & EnsEMBLPlants & http://plants.ensembl.org/index.htm/ \\
\hline & Brachypodiumdb & http://db.brachypodium.org/ \\
\hline & $\mathrm{EBI}$ & http://www.ebi.ac.uk/emb// \\
\hline & GenBank & http://www.ncbi.n/m.nih.gov/genbank/ \\
\hline & Gramene & http://www.gramene.org/ \\
\hline & Oryzabase & http://www.shigen.nig.ac.jp/rice/oryzabase/ \\
\hline & GrainGenes & http://wheat.pw.usda.gov/ \\
\hline \multirow{6}{*}{$\begin{array}{l}\text { Large-scale } \\
\text { collections of full- } \\
\text { length cDNA } \\
\text { clones }\end{array}$} & flcDNA A. thaliana & http://rarge.psc.riken.jp/ \\
\hline & flcDNA O. sativa & $\begin{array}{l}\text { http://cdna01.dna.affrc.go.jp/cDNA/ } \\
\text { http://www.ncgr.ac.cn/ricd }\end{array}$ \\
\hline & flcDNA H. vulgare & http://www.shigen.nig.ac.jp/barley/ \\
\hline & flcDNA $T$. aestivum & http://trifldb.psc.riken.jp/index.pl \\
\hline & flcDNA Z. mays & http://www.maizecdna.org/ \\
\hline & ViroBLAST & $\begin{array}{l}\text { http://indra.mullins.microbiol.washington.edu/viroblast/ } \\
\text { viroblast.php }\end{array}$ \\
\hline \multirow[t]{3}{*}{ TF databases } & AGRIS & http://arabidopsis.med.ohio-state.edu/ \\
\hline & PlantTFDB & http://planttfdb.cbi.edu.cn/ \\
\hline & GRASSIUS & http://grassius.org/ \\
\hline \multirow{5}{*}{$\begin{array}{l}\text { Microarray bulk } \\
\text { data retrieval }\end{array}$} & NASCarrays & http://affymetrix.arabidopsis.info/narrays/experimentbrowse.pl \\
\hline & ArrayExpress & http://www.ebi.ac.uk/arrayexpress/ \\
\hline & AtGenExpress & http://www.weige/world.org/resources/microarray/AtGenExpress/ \\
\hline & GEO & http://www.ncbi.n/m.nih.gov/geo/ \\
\hline & PlexDB & http://www.plexdb.org/ \\
\hline \multirow{3}{*}{$\begin{array}{l}\text { Gene expression } \\
\text { analysis resources }\end{array}$} & Genevestigator & https://www.genevestigator.com/gv/ \\
\hline & BAR & http://esc4037-shemp.csb.utoronto.ca/welcome.htm \\
\hline & eFP Browser & http://esc4037-shemp.csb.utoronto.ca/efp/cgi-bin/efpWeb.cgi \\
\hline \multirow{3}{*}{$\begin{array}{l}\text { Functional } \\
\text { information }\end{array}$} & GeneMANIA & http://www.genemania.org/ \\
\hline & IntACT & http://www.ebi.ac.uk/intact/ \\
\hline & BioGRID & http://thebiogrid.org/ \\
\hline
\end{tabular}

Table 2. Web-based resources for gene expression analysis for Arabidopsis and other species, including crops. 
In many cases, not only structural proteins, such as ion channels are conserved between Arabidopsis and other plant species, but also regulatory proteins, such as transcription factors. In addition, it is worth adding that entire transcriptional regulons can also be conserved, as in case of the ABA signalosome PYR/PYL/RCAR-PP2Cs-SNRKs. 'Only after we understand how plants respond to stress - in many cases first in Arabidopsis and then applying the Arabidopsis model to crop plants - will we be able to begin engineering stress tolerance' [100].

During the last decade, microarrays have become a routine tool for the analysis of transcripts, not only in model Arabidopsis but also in crops, such as barley and rice. Interestingly, interspecies comparisons between distantly related species, Arabidopsis and rice or barley revealed conserved patterns of expression in the case of many orthologs genes [101-103]. Comparative analyses showed that orthologous of specific genes in rice or barley are also responsive to stress similar to Arabidoposis [103; 102]. Mochida et al. [104] used publicly available transcriptome data to investigate regulatory networks of the genes involved in various developmental aspects including drought in barley. On the basis of a comparative analysis between barley and model species, such as Arabidopsis or Brachypodium, modules of genes putatively involved in drought response have been identified. In addition to these computational approaches, Moumeni et al. [105] have undertaken a comparative analysis of the rice root transcriptome under drought stress. They used two pairs each of drought-tolerant and susceptible rice NILs (Near Isogenic Lines). Global gene expression analysis revealed that about $55 \%$ of the genes differentially expressed were in rice roots under drought stress. The drought-tolerant lines showed an up-regulation of the genes involved in secondary metabolism, amino acid metabolism, response to stimulus, defense response, transcription and signal transduction. Proteomic analysis of drought-sensitive and drought-tolerant barley lines performed by Kausar et al. [106] revealed an increased level of metabolism, photosynthesis and amino acid synthesis-related proteins in tolerant genotypes, whereas a decreased level was observed in sensitive forms. The data confirmed the results described previously in other species and should that similar processes play a significant role in barley's adaptation to stress conditions.

\section{The huge role of tiny molecules (microRNA) in drought response}

Small non-coding RNAs - miRNAs, which were first reported in the nematode Ceanorhabditis elegans in 1993 [107] and which are responsible for the phenomenon of RNA interference, have become recognized as very important regulatory components of the cell signaling. miRNAs have been shown to be highly conserved gene expression regulators across species [108-109]. The first plant miRNA was isolated from Arabidopsis [110]. To date, approximately 5000 plant miRNAs have been identified and deposited in miRbase (19.0 release) including 299 miRNA from Arabidopsis, 135 from Brachypodium, 206 from sorghum, 42 from wheat, 591 from rice, 172 from maize and 67 from barley [111]. miRNAs are small regulatory RNAs of a 20-22 nucleotide length that are encoded by endogenous MIR genes. Their primary transcripts are partially double-stranded stem-loop structures. Pri-miRNAs in plants 
are processed by DCL1 (DICER-LIKE 1) HYL1 (HYPONASTIC LEAVES 1), SE (SERRATED) proteins into pre-miRNA hairpin precursors which are finally converted into short duplexes - mature miRNAs. The duplexes are then methylated at the $3^{\prime}$ terminus and exported to the cytoplasm. In the cytoplasm, single-stranded miRNAs are incorporated in the AGO (ARGONAUTE) protein, the catalytic compound of the RISC (RNA-INDUCED SILENCING COMPLEX) complex, and guide the RISC to the target mRNAs by sequence complementarity to negatively regulate their expression [112].

Plant microRNAs are involved in various developmental processes including flowering, and leaf, stem and root development [113-115]. Jones-Rhoades and Bartel [116] drew the attention of plant biologists to the miRNA engagement in stress response for the first time. To gain an insight into the role of miRNAs in the regulation of transcripts in response to drought, several projects on the identification of the miRNAs related to stress response in crops were undertaken. Using deep sequencing techniques, Zhou et al [117] identified nineteen new miRNAs that are induced by drought in rice, among them eleven down-regulated and eight up-regulated miRNAs. In addition, they identified nine miRNAs that showed an opposite expression to that observed in drought-stressed Arabidopsis (Table 3). A similar approach was used by Kulcheski et al. [118] in soybean, which revealed 11 miRNAs that are related to drought stress (Table 3). Based on bioinformatic prediction and then verification of the obtained results using RT-qPCR, Xu et al. [119] identified 21 miRNAs differently expressed during water stress in maize (Table 3). A similar approach using bioinformatic prediction of miRNAs on dehydration stress was undertaken by Kantar et al. [7], who found four miRNAs that are related to drought stress in barley (Table 3). Deep sequencing of a small RNA library in the case of barley was performed by Lv et al. [8]. They showed that six miRNAs specific for stress response. hvu-MIRn026a, hvu-MIRn029, hvu-MIR035, hvuMIR156d exhibited higher expression in response to salt and drought stress, whereas hvuMIR396d and hvu-MIR399b showed a higher expression only in drought-stressed plants. Additionally, the authors observed that hvu-mir029 was highly expressed after drought treatment and at a very low level under non-stressed conditions, which suggests the important role of this molecule in water deficit response (Table 3).

To understand the function of newly identified miRNAs, the putative target transcripts have to be predicted. In order to identify microRNAs target transcripts, Kantar et al [7] performed computational studies and a modified 5' RLM-RACE (RNA ligase-mediated 5' rapid amplification of cDNA ends) in barley. Seven cleaved miRNA transcripts were retrieved from drought-stressed leaf samples as targets for hvu-MIR165, hvu-MIR166, hvu-MIR156, hvuMIR2055, hvu-MIR171, hvu-MIR172, hvu-MIR397 and hvu-MIR159. The identified targets are mainly transcription factors that play a role in plant development, morphology and determination of the flowering time. SCRL6 (SCARECROW LIKE 6) encodes a transcription factor that is involved in diverse plant developmental processes such as leaf or root growth and is the target of hvu-MIR171, ARF10 (AUXIN RESPONSIVE FACTOR 10) encodes a transcription factor that negatively regulates auxin signaling and is the target of hvu-MIR160, SBP (SQUAMOSA PROMOTER BINDING PROTEIN) is a transcription factor that is mainly important for leaf development and is the target of hvu-MIR156a, and MYB33 (MYB DOMAIN 
PROTEIN 33) is a transcription factor that is involved in ABA and GA signaling and is the target of hvu-MIR159a [7].

\begin{tabular}{|c|c|c|}
\hline Species & Identified miRNA related to drought & References \\
\hline rice & $\begin{array}{l}\text { osa-MIR170, osa-MIR172, osa-MIR397, osa-MIR408, } \\
\text { osa-MIR529, osa-MIR896, osa-MIR1030, osa-MIR1035, osa-MIR1050, } \\
\text { osa-MIR1088, osa-MIR1126, osa-MIR395, osa-MIR474, osa-MIR845, } \\
\text { osa-MIR851, osa-MIR854, osa-MIR901, osa-MIR903 and osa-MIR1125, } \\
\text { osa-MIR156, osa-MIR168, osa-MIR170, osa-MIR171, osa-MIR172, osa- } \\
\text { MIR319, osa-MIR396, osa-MIR397, osa-MIR408 }\end{array}$ & [117] \\
\hline soybean & $\begin{array}{l}\text { gma-MIR166-5p, gma-MIR169f-3p, gma-MIR1513c, } \\
\text { gma-MIR397ab, gma-MIR-Seq13, gma-MIR-Seq11, } \\
\text { gma-MIRSeq15, gma-MIR166f, gma-MIR-482bd-3p, } \\
\text { gma-MIR4415b, gma-MIR-Seq07 }\end{array}$ & [118] \\
\hline maize & $\begin{array}{l}\text { zma-MIR161, zma-MIR397, zma-MIR446, zma-MIR479, zma-MIR530, } \\
\text { zma-MIR776, zma-MIR782, zma-MIR815a, zma-MIR818a, zma- } \\
\text { MIR820, zma-MIR828, zma-MIR834, zmaMIR1, zma-MIR2, zma-MIR3, } \\
\text { zma-MIR4, zma-MIR5, zma-MIR6, zma-MIR7, zma-MIR8, zma-MIR9 }\end{array}$ & [119] \\
\hline \multirow[t]{2}{*}{ barley } & hvu-MIR156, hvu-MIR166, hvu-MIR171, hvu-MIR408 & [7] \\
\hline & $\begin{array}{l}\text { hvu-MIRn026a, hvu-MIRn029, hvu-MIR035, hvu-MIR156d, hvu- } \\
\text { MIR396d, hvu-MIR399b }\end{array}$ & {$[8]$} \\
\hline
\end{tabular}

Table 3. miRNA related to drought in different crop species.

\section{From the cell to the organism level - Phenotyping of drought-treated crops}

In order to understand gene-to-phenotype relationships in the plant response to drought stress, it is vital to decipher the physiological and genetic bases of this process. Recent advances in crop physiology, genomics and plant phenotyping have provided a broader knowledge and better tools for crop improvement under stress conditions [120]. Maintaining a high yield under drought conditions has become a priority for breeders. However, the physiological basis of yield maintenance under drought is not yet fully understood, of the complexity of the mechanisms that plants can use to maintain growth in conditions due to water deficit [120]. Quantitative trait loci (QTL) for genes conferring a yield benefit under drought conditions first need to be identified in phenotypic screens and then incorporated into crops using marker-assisted selection [121]. Direct selection for yield in drought-prone environments, however, has proven to be difficult. Drought stress is a dynamic process and 
can occur at different periods of the crop cycle and with different intensities. Consequently, plants have developed various strategies in response to drought: tolerance, escape and avoidance. Ludlow [122] defined three strategies plants use to cope with drought stress: drought tolerance is the ability of a plant to cope with water deficit through low tissue water potential, drought escape is defined as completion of the life cycle just before a severe drought starts, and drought avoidance is plant maintenance of high tissue water potential by minimizing water loss or maximizing water uptake. The final mechanism conveys the ability to survive and recover rapidly after a severe stress through protective mechanisms, such as cell wall folding, membrane protection, and the accumulation of antioxidants [123-124].

In order to incorporate traits that confer drought tolerance into molecular breeding programs, phenotyping protocols are extremely important [125]. With the wide availability of genetic resources, such as mutant populations (TILLING) or mapping populations, high-throughput phenotyping will become an essential asset in closing the gap between plant physiology and genetics [126- 127]. It is worth noting that a complex set of both abiotic and biotic stresses shapes the natural environment during plant development drought stress is just one of many factors. It is hard to exclude one of the stress pathways and to analyze it in isolation from others because the cascade of stress response is a complicated web of overlapping pathways. When studying drought tolerance in plants, it is very difficult to control and monitor the level and onset of water deficit, since it is a dynamic process and a combination of the available water in the soil and the plant water status. Continuous measurements are needed in order to link the level of drought experienced by the plant with the physiological changes occurring in response to it [125]. Under greenhouse conditions, water use can be monitored by weighing the pots or using TDR (Time Domain Reflectometry) soil moisture meters [128]. The water supply can be regulated at high-throughput automated screening facilities by using the classical water withdrawal approach [14] and maintaining a constant soil water status [129].

Another difficult issue is how to describe plant response to drought at the physiological level using properly chosen physiological, but also morphological, traits. In breeding programs for improved drought tolerance, crop traits associated with the conceptual framework for yield drought adaptation have been proposed by Passioura [130]. This framework has three important drivers: (1) water uptake (WU), (2) water-use efficiency (WUE) and (3) harvest in$\operatorname{dex}(\mathrm{HI})$. Several traits are highly associated with these three aspects of Passioura model. With regard to $\mathrm{WU}$, the best method would be direct selection for variation in root architecture but since this is hard to perform, stomatal conductance, mainly the canopy temperature, is measured. This provides indirect indicators of water uptake by roots [131]. To estimate WUE, carbon isotope discrimination is used. A high affinity of Rubisco for the more common ${ }^{12} \mathrm{C}$ isotope over the ${ }^{13} \mathrm{C}$ indicates a lower WUE, whereas a lower discrimination value indicates a higher WUE [131]. In the case of HI, the extreme sensitivity of reproductive processes to drought may result in reproductive failure, which is associated with a low $\mathrm{HI}$ value [132]. 
Water stress reduces photosynthesis in the leaves of higher plants. It is linked with a decreased diffusion of $\mathrm{CO}_{2}$ from the atmosphere to the site of carboxylation [133-134]. Underlying this process is the stomatal closure during short-term drought and photoinhibition damage, and the inactivation of RuBisCO under long-term stress [135].

Stomatal closure is one of the first responses to drought conditions which might result in cell dehydration or runaway xylem cavitation [136]. A good illustration of this process is stomatal behavior in the midday, when either stomatal closure or decreased stomatal conductance can be observed. Both responses are mediated by ABA synthesized in response to dehydration conditions [18]. When decreased stomatal conductance is combined with sustained high irradiance, leaves are subjected to excess energy relative to the available $\mathrm{CO}_{2}$ and the rate of reducing power can overcome the rate of its use in the Calvin cycle. These processes lead to the down-regulation of photosynthetic and even photoinhibition. Plants have evolved mechanisms of defense to protect photosynthesis. Such protection can be achieved by the regulated thermal dissipation that occurs in the lightharvesting complexes [137].

Processes associated with the photosynthetic apparatus can be measured using chlorophyll fluorescence. Experiments with chlorophyll fluorescence were first carried out by Kautsky and Hirsch [138]. Since then, this technique has progressed quickly and chlorophyll fluorescence can be easily measured using commercially available chlorophyll fluorimeters which enable the measurements of the photochemical and non-photochemical processes involved in the fluorescence quenching that occurs in the presence of light [139]. The Fv/Fm ratio representing the maximum quantum yield of the primary photochemical reaction of photosystem II (PSII) is the most often used parameter. Environmental stresses that affect PSII efficiency lead to the characteristic decrease in the value of this parameter [140]. Fluorescence kinetics of chlorophyll a, the 'OJIP/JIP-test' named after the basic steps of the transient by which parameters quantifying PSII behavior are calculated ( $\mathrm{O}$ is the fluorescence intensity F0 (at $50 \mu \mathrm{s}) ; \mathrm{J}$ is the fluorescence intensities FJ (at $2 \mathrm{~ms}$ ); I is FI (at $30 \mathrm{~ms}$ ) and P is the maximal fluorescence intensity, FP = FM) is an informative tool for studying the effects of different environmental stresses on photosynthesis [141-142;10;143]. This analysis offers simple equations to express the equilibrium between the inflow and outflow of the entire energy flux within PSII; it also provides information about the fate of absorbed energy. Some of the parameters calculated using the JIP-test are related to energy fluxes for light absorption (ABS), the trapping of excitation energy (TR) and electron transport (ETR) per reaction center $(\mathrm{RC})$ or per sample area called cross-section (CS). Their estimates are based on the analysis of several groups of measured and calculated parameters. Analyses performed using these parameters are quick and the measurements are non-invasive [10].

In addition to the photosynthesis process, it was observed that the alteration of leaf angle caused by dehydration, towards smaller angles, would diminish intercepted radiation and carbon assimilation, and also have an important protective role against excess solar energy [144]. There is also a correlation between the rate of photosynthesis and the age of the leaf. Younger leaves tend to be more resistant to drought than older ones. When a severe reduction in the size of the leaf canopy occurs, as a result of shedding older 
leaves, it allows a plant to recover faster following rehydration [145]. Photosynthetic recovery following rehydration plays a pivotal role in drought-tolerance mechanisms and prevents a dramatic decline in crop yields [146]. It was shown that recovery from a severe stress is a two-step process. The first phase occurs during the first hours or days after rewatering and corresponds to an improvement of leaf water status and the reopening of stomata [147]. The second stage lasts a few days and requires the de novo synthesis of photosynthetic proteins [148-149].

It is also worth noting that other phenotype analyses should be performed in order to obtain a complete picture of the stress response of a given plant. Relative Water Content (RWC), which was proposed by Sinclair and Ludlow [12], is the most often used assay to assess plant response to a water deficit. This simple test allows the establishment of relative water content in a leaf of control and drought-treated plants. Detached leaves are weighed and saturated with water for $24 \mathrm{~h}$, then again weighed and dried for $48 \mathrm{~h}$ and weighed again. RWC is calculated from the following formula: $\operatorname{RWC}(\%)=[(\mathrm{FM}-\mathrm{DM}) /(\mathrm{TM}-\mathrm{DM})]{ }^{*} 100$, where, FM, DM, and TM are the fresh, dry and turgid masses of the tissue weighted, respectively.

The degree of cell membrane stability (CMS) is considered to be one of the best physiological indicators of drought-stress tolerance. It can be evaluated using measurements of solute leakage from plant tissue [150-151].

In response to drought stress, plants are able to adjust osmotic pressure by synthesizing osmoprotectants such as proline, the water soluble carbohydrates that behave like a molecular weapon against dehydration within the cell. There are several methods used in order to estimate the accumulation of endogenous proline or sugars in drought-treated plants [152].

Several morphological traits that have an impact on drought tolerance have been observed. Growth inhibition resulting from drought-induced ABA biosynthesis was observed in plants exposed to stress [153]. A number of studies have shown that wax deposition on the leaf surface increased in response to drought and an associated improvement in drought tolerance was observed in oat, rice, sorghum, wheat and barley plants that had an increased wax layer [154 -157]. Enhanced drought tolerance was also gained by plants having a reduced number of stomata, which was probably dependent on the accumulation of waxes [158]. Yang et al [158] performed analysis on an ox-win1/ shn1 (overexpressor wax inducer 1/shine 1) mutant. WIN1/SHN1 encodes a transcription factor that regulates the expression of genes that control the accumulation of cuticular wax. Analyses performed by Yang et al [158] showed that induction of WIN1/SHN1 expression by drought is correlated with an increased expression of the genes involved in wax accumulation, and on the other hand, a decreased expression of the genes involved in stomatal development. These results suggest that the drought-tolerant phenotype of analyzed by Yang et al [158] forms caused by induction of WIN1/SHN1 may be due to a reduced number of stomata as well as wax accumulation.

There are now several high-throughput phenotyping techniques available for the measurement of some of the traits described above. One of these is thermal infrared imaging, or infrared thermography (IRT), which is used to measure the leaf or canopy temperature. 
Evaporation is a main determinant of leaf temperature. There is a direct relationship between leaf temperature, transpiration rate and stomatal conductance [159-161]. Drought-tolerant genotypes can maintain a higher stomatal conductance and also a higher rate of photosynthesis, as was mentioned above, thus these genotypes could be identified as having a lower canopy temperature than the sensitive genotypes [162-163].

\section{GM crops - are they a solution?}

Genetic modification of crops is a controversial issue. Some aspects of genetic modification that have potential to improve drought tolerance in crops are presented here. Biotechnological approaches may involve the overexpression of genes related to osmotic adjustment, chaperones and antioxidants [reviewed in 164-165]. Also, ectopic expression or suppression of regulatory genes, such as genes that encode transcription factors, is widely used [166]. Recent studies on rice led to the identification of genes involved in three pathways that can be manipulated in order to improve drought tolerance in crops: the gene that encodes $\beta$-carotene hydroxylase, which confers drought resistance by increasing xanthophylls and ABA synthesis [167], the DST1 (DROUGHT AND SALT TOLERANT 1) gene that regulates stomatal closure and density under drought stress [168] and the TLD1/ OsGH3.13 (INCREASED NUMBER OF TILLERS, ENLARGED LEAF ANGLES, AND DWARFISM) gene whose downregulation enhanced drought tolerance in rice [169]. Although several genes that can improve the drought tolerance of crops have already been identified, progress in the commercialization of the traits controlled by these genes has been slow [165]. One of the genes that has been successfully introduced into a crop plant and that gave improved drought tolerance in field trials was the gene encoding Cold Shock Protein B (CspB) RNA chaperone from Bacillus subtilis. The $\operatorname{CspB}$ gene is important in the ability of bacteria to adapt to cold, and its overexpression in plants was shown to provide drought tolerance in Arabidopsis, rice and maize [170]. Results from field experiments showed that a maize line expressing the $C s p B$ gene had a higher yield under water deficit conditions than the control and expressed a yield equivalent to the control under non-stressed conditions. Tests are in progress in 2012 on commercial farms, [171; http://www.monsanto.com/products/Pages/ corn-pipeline.aspx\#firstgendroughttolerantcorn]. The value of a biotechnological approach to improving crop yields under drought stress conditions is becoming evident with the first demonstrations of improved drought tolerance in crops in the field (reviewed in [171]).

\section{Conclusions and perspectives}

In order to achieve a full understanding of drought-response mechanisms in plants and to make use of this understanding to produce crops with improved drought tolerance, there is a need to combine the data derived from different studies. Detailed analyses of the networks of protein interactions, the co-expression of genes, metabolic factors, etc. should provide insights into the key regulators of drought response [172-173]. Biotechnological approaches 
can also be promising in improving drought tolerance in crops based on previously obtained and integrated knowledge [171].

\section{Acknowledgements}

This work was supported by the European Regional Development Fund through the Innovative Economy for Poland 2007-2013, project WND-POIG.01.03.01-00-101/08 POLAPGENBD "Biotechnological tools for breeding cereals with increased resistance to drought", task 22. The project is realized by POLAPGEN Consortium and is coordinated by the Institute of Plant Genetics, Polish Academy of Sciences in Poznan. Further information about the project can be found at www.polapgen.pl.

\section{Author details}

Agata Daszkowska-Golec and Iwona Szarejko

Department of Genetics, Faculty of Biology and Environmental Protection, University of Silesia, Katowice, Poland

\section{References}

[1] Ma Y, Szostkiewicz I, Korte A, Moes D, Yang Y, Christmann A, Grill E. Regulators of PP2C phosphatase activity function as abscisic acid sensors. Science 2009; 324: 1064 1068.

[2] Park SY, Fung P, Nishimura N, et al. Abscisic acid inhibits type 2C protein phosphatases via the PYR/PYL family of START proteins. Science 2009; 324: 1068-1071.

[3] Santiago J, Dupeux F, Round A, Antoni R, Park S-Y, et al. The abscisic acid receptor PYR1 in complex with abscisic acid. Nature 2009; 462: 665-668.

[4] Nishimura N, Sarkeshi A, Nito K et al. PYR/PYL/RACR family members are major in vivo ABI1 protein phosphatase 2C interacting proteins in Arabidopsis. Plant J. 2010; 61: 290-299.

[5] Ye N., Jia L. and J. Zhang. ABA signal in rice under stress conditions. Rice. 2012; 5:1 doi:10.1186/1939-8433-5-1.

[6] Wilkinson S, Kudoyarova GR, Veselov DS, Arkhipova TN, Davies WJ. Plant hormone interactions: innovative targets for crop breeding and management. J Exp Bot. 2012; 63(9): 3499-509. 
[7] Kantar M, Unver T, Budak H. Regulation of barley miRNAs upon dehydration stress correlated with target gene expression. Funct Integr Genomics. 2010; 10(4): 493-507.

[8] Lv S, Nie X, Wang L, Du X, Biradar SS, Jia X, Weining S. Identification and characterization of microRNAs from barley (Hordeum vulgare L.) by high-throughput sequencing. Int J Mol Sci. 2012; 13(3):2973-84.

[9] Munns R, James RA, Sirault XR, Furbank RT, Jones HG. New phenotyping methods for screening wheat and barley for beneficial responses to water deficit. J Exp Bot. 2010; 61(13): 3499-507.

[10] Strasser, R.J., Srivastava, A., Tsimilli-Michael, M. The fluorescence transient as a tool to characterize and screen photosynthetic samples. In: Yunus, M., Pathre, U., Mohanty, P. (Eds.), Probing Photosynthesis: Mechanisms, Regulation and Adaptation. Taylor \& Francis, London, 2000. pp. 445-483.

[11] Kalaji MH, Bosa K, Kościelniak J, Hossain Z. Chlorophyll a fluorescence - a useful tool for the early detection of temperature stress in spring barley (Hordeum vulgare L.). OMICS A Journal of Integrative Biology. 2011; 15 (12): 925-934.

[12] Sinclair TR, Ludlow MM. Who taught plants thermodynamics? The unfulfilled potential of plant water potential. Aust J Plant Physiol 1985; 12:213-217.

[13] Addicott, FT, Carns HR, Lyon JL, Smith OE, Micm Eans JL. On the physiology of abscisins. In: J. P. Nitsch, ed., Regulateurs Naturels de la Croissance. Centre National de la Recherche Scientifique. Paris. 1964. pp. 687-703.

[14] Iuchi S, Kobayashi M, Taji T, Naramoto M, Seki M, Kato T, Tabata S, Kakubari Y, Yamaguchi-Shinozaki K, Shinozaki K. Regulation of drought tolerance by gene manipulation of 9-cis-epoxycarotenoid dioxygenase, a key enzyme in abscisic acid biosynthesis in Arabidopsis. Plant J. 2001; 27: 325-333.

[15] Qin X, Zeevaart J. The 9-cis-epoxycarotenoid cleavage reaction is the key regulatory step of abscisic acid biosynthesis in water-stressed bean. Proc Natl Acad Sci USA. 1999; 96: 15354-15361.

[16] Zhu JK. Salt and drought stress signal transduction in plants. Annu. Rev. Plant Biol. 2002; 53: 247-273.

[17] Davies WJ, Wilkinson S, Loveys BR. Stomatal control by chemical signalling and the exploitation of this mechanism to increase water use efficiency in agriculture. New Phytologist. 2002; 153: 449-460.

[18] Wilkinson S, Davies WJ. Drought, ozone, ABA and ethylene: new insights from cell to plant to community. Plant, Cell and Environment. 2010; 33: 510-525.

[19] Giuliani S, Sanguineti MC, Tuberosa R, Bellotti M, Salvi S, Landi P. Root-ABA1 a major constitutive QTL affects maize root architecture and leaf ABA concentration at different water regimes. Journal of Experimental Botany. 2005; 56: 3061-3070. 
[20] Seo M, Koshiba T. 2002. Complex regulation of ABA biosynthesis in plants. Trends Plant Sci. 2002; 7(1): 41-48.

[21] Tan, B.C., Schwartz, S.H., Zeevaart, J.A., and McCarty, D.R. Genetic control of abscisic acid biosynthesis in maize. Proc. Natl. Acad. Sci. USA. 1997; 94: 12235-12240.

[22] Burbidge, A., Grieve, T.M., Jackson, A., Thompson, A., McCarty, D.R., and Taylor, I.B. Characterization of the ABA-deficient tomato mutant notabilis and its relationship with maize vp14. Plant J. 1999; 17, 427-431.

[23] Destefano-Beltrán L, Knauber D, Huckle L, Suttle JC. Effects of postharvest storage and dormancy status on ABA content, metabolism, and expression of genes involved in ABA biosynthesis and metabolism in potato tuber tissues. Plant Mol Biol. 2006; 61(4-5): 687-97.

[24] Seiler C, Harshavardhan VT, Rajesh K, Reddy PS, Strickert M, Rolletschek H, Scholz U, Wobus U, Sreenivasulu N. ABA biosynthesis and degradation contributing to ABA homeostasis during barley seed development under control and terminal drought-stress conditions. J Exp Bot. 2011; 62(8): 2615-32.

[25] Taylor IB, Burbidage A, Thompson AJ. Control of abscisic acid synthesis. J Exp Bot. 2000; 51: 1563-1574

[26] Finkelstein RR, Rock CD. Abscisic acid biosynthesis and response. In CR Somerville, EM Meyerowitz, eds, The Arabidopsis Book. American Society of Plant Biologists, Rockville, MD. 2002. pp 1-52

[27] Schwartz SH, Qin X, Zeevaart J. Elucidation of the indirect pathway of abscisic acid biosynthesis by mutants, genes, and enzymes. Plant Physiol. 2003; 131: 1591-1601.

[28] Marin E, Nussaume L, Quesada A, Gonneau M, Sotta B, Hugueney P, Frey A, Marion-Poll A. Molecular identification of zeaxanthin epoxidase of Nicotiana plumbaginifolia, a gene involved in abscisic acid biosynthesis and corresponding to the ABA locus of Arabidopsis thaliana. EMBO J. 1996; 15: 2331-2342.

[29] North HM, De Almeida A, Boutin JP, Frey A, To A, Botran L, Sotta B, Marion-Poll A. The Arabidopsis ABA-deficient mutant aba4 demonstrates that the major route for stress-induced ABA accumulation is via neoxanthin isomers. Plant J. 2007; 50: 810 824

[30] Schwartz SH, Tan BC, Gage DA, Zeevaart JAD, McCarty DR. Specific oxidative cleavage of carotenoids by VP14 of maize. Science. 1997; 276: 1872-1874

[31] Rook F, Corke F, Card R, Munz G, Smith C, Bevan MW. Impaired sucrose-induction mutants reveal the modulation of sugar-induced starch biosynthetic gene expression by abscisic acid signaling. Plant J. 2001; 26: 421-433.

[32] Cheng WH, Endo A, Zhou L, Penney J, Chen HC, Arroyo A, Leon P, Nambara E, Asami T, Seo M et al. A unique short-chain dehydrogenase/reductase in Arabidopsis 
glucose signaling and abscisic acid biosynthesis and functions. Plant Cell. 2002; 14: 2723-2743.

[33] Gonzalez-Guzman M, Apostolova N, Belles JM, Barrero JM, Piqueras P, Ponce MR, Micol JL, Serrano R, Rodriguez PL. The short-chain alcohol dehydrogenase ABA2 catalyzes the conversion of xanthoxin to abscisic aldehyde. Plant Cell. 2002; 14: 1833-1846.

[34] Seo M, Aoki H, Koiwai H, Kamiya Y, Nambara E, Koshiba T. Comparative studies on the Arabidopsis aldehyde oxidase (AAO) gene family revealed a major role of AAO3 in ABA biosynthesis in seeds. Plant Cell Physiol. 2004; 45: 1694-1703.

[35] Burbidge A, Grieve TM, Jackson A, Thompson A, McCarty DR, Taylor IB. Characterization of the ABA-deficient tomato mutant notabilis and its relationship with maize vp14. Plant J. 1999. 17: 427-431.

[36] Chernys JT, Zeevaart JA. Characterization of the 9-cis-epoxycarotenoid dioxygenase gene family and the regulation of abscisic acid biosynthesis in avocado. Plant Physiol. 2000; 124: 343-353.

[37] Thompson AJ, Jackson AC, Parker RA, Morpeth DR, Burbidge A, Taylor IB. Abscisic acid biosynthesis in tomato: regulation of zeaxanthin epoxidase and 9-cis-epoxycarotenoid dioxygenase mRNAs by light/dark cycles, water stress and abscisic acid. Plant Mol Biol. 2000; 42: 833-845.

[38] Ye N, Zhu G, Liu Y, Li Y, Zhang J. ABA Controls $\mathrm{H}_{2} \mathrm{O}_{2}$ accumulation through the induction of OsCATB in rice leaves under water stress. Plant Cell Physiol. 2011; 52:689-698.

[39] Endo, A., et al. Drought induction of Arabidopsis 9-cis-epoxycarotenoid dioxygenase occurs in vascular parenchyma cells. Plant Physiol. 2008; 147: 1984-1993.

[40] Kushiro T, Okamoto M, Nakabayashi K, Yamagishi K, Kitamura S, Asami T, et al. The Arabidopsis cytochrome P450 CYP707A encodes ABA 8'-hydroxylases: key enzymes in ABA catabolism. EMBO J. 2004; 23:1647-1656.

[41] Umezawa T, Okamoto M, Kushiro T, Nambara E, Oono Y, Seki M, Kobayashi M, Koshiba T, Kamiya Y, Shinozaki K. CYP707A3, a major ABA 8'-hydroxylase involved in dehydration and rehydration response in Arabidopsis thaliana. The Plant Journal. 2006; 46:171-182.

[42] Saika, H., Okamoto, M., Miyoshi, K., Kushiro, T., Shinoda, S., Jikumaru, Y., et al. Ethylene promotes submergence-induced expression of OsABA8ox1, a gene that encodes ABA 8' -hydroxylase in rice. Plant Cell Physiol. 2007; 48: 287- 298.

[43] Millar AA, Jacobsen JV, Ross JJ, Helliwell CA, Poole AT, Scofield G, Reid JB, Gubler F. Seed dormancy and ABA metabolism in Arabidopsis and barley: the role of ABA 8'-hydroxylase. Plant J. 2006; 45(6):942-54.

[44] Ji X., Dong B, Shiran B, Talbot M J., Edlington J. E., Hughes T., White R. G., Gubler F. and R. Dolferus. Control of abscisic acid catabolism and abscisic acid homeostasis is 
important for reproductive stage stress tolerance in cereals. Plant Physiology 2011; 156 (2): 647-662.

[45] Zheng Y, Huang Y, Xian W, Wang J, Liao H. Identification and expression analysis of the Glycine max CYP707A gene family in response to drought and salt stresses. Ann Bot. 2012.

[46] Dietz KJ, Sauter A, Wichert K, Messdaghi D, Hartung W. Extracellular $\beta$-glucosidase activity in barley involved in the hydrolysis of ABA glucose conjugate in leaves. J Exp Bot. 2000; 51: 937-944.

[47] Boyer GL, Zeevaart J. Isolation and quantitation of $\beta$-D-glucopyranosyl abscisate from leaves of Xanthium and spinach. Plant Physiol. 1982; 70: 227-231.

[48] Xu ZJ, Nakajima M, Suzuki Y, Yamaguchi I. Cloning and characterization of the abscisic acid-specific glucosyltransferase gene from adzuki bean seedlings. Plant Physiol. 2002; 129: 1285-1295.

[49] Lee KH, Piao HL, Kim HY, Choi SM, Jian F, Hartung W, et al. Activation of glucosidase via stress-induced polymerization rapidly increased active pools of abscisic acid. Cell. 2006; 126: 1109-1120.

[50] Salisbury FB, Ross CW. Plant Physiology. Wadsworth Publishing Company, Belmont, California. 1985. p 312.

[51] Kang J, Hwang JU, Lee M, Kim YY, Assmann SM, Martinoia E, Lee Y. PDR-type ABC transporter mediates cellular uptake of the phytohormone abscisic acid. Proc Natl Acad Sci USA. 2010; 107: 2355-2360

[52] Kuromori T, Sugimoto E, Shinozaki K. Arabidopsis mutants of AtABCG22, an ABC transporter gene, increase water transpiration and drought susceptibility. Plant J. 2011; 67: 885-894.

[53] Kuromori T, Miyaji T, Yabuuchi H, Shimizu H, Sugimoto E, Kamiya A, et al. ABC transporter AtABCG25 is involved in abscisic acid transport and responses. Proc Natl Acad Sci USA. 2010; 107: 2361-2366.

[54] Fujii H, Zhu JK. Arabidopsis mutant deficient in 3 abscisic acid-activated protein kinases reveals critical roles in growth, reproduction, and stress. Proc Natl Acad Sci USA. 2009; 106(20): 8380-5.

[55] Fujita Y, Nakashima K, Yoshida T, Katagiri T, Kidokoro S, Kanamori N, Umezawa T, Fujita M, Maruyama K, Ishiyama K, Kobayashi M, Nakasone S, Yamada K, Ito T, Shinozaki K, Yamaguchi-Shinozaki K. Three SnRK2 protein kinases are the main positive regulators of abscisic acid signaling in response to water stress in Arabidopsis. Plant Cell Physiol. 2009; 50(12): 2123-32.

[56] Umezawa T, Sugiyama N, Mizoguchi M, Hayashi S, Myouga F, Yamaguchi-Shinozaki K, Ishihama Y, Hirayama T, Shinozaki K. Type 2C protein phosphatases directly 
regulate abscisic acid-activated protein kinases in Arabidopsis. Proc Natl Acad Sci U S A. 2009; 106(41): 17588-93.

[57] Vlad F, Rubio S, Rodrigues A, Sirichandra C, Belin C, Robert N, Leung J, Rodriguez PL, Laurière C, Merlot S. Protein phosphatases $2 \mathrm{C}$ regulate the activation of the Snf1related kinase OST1 by abscisic acid in Arabidopsis. Plant Cell. 2009; (10): 3170-84.

[58] Mustilli AC, Merlot S, Vavasseur A, Fenzi F, Giraudat J. Arabidopsis OST1 protein kinase mediates the regulation of stomatal aperture by abscisic acid and acts upstream of reactive oxygen species production. Plant Cell. 2002; 14(12): 3089-99.

[59] Fujii H, Verslues PE, Zhu JK. Identification of two protein kinases required for abscisic acid regulation of seed germination, root growth, and gene expression in Arabidopsis. Plant Cell. 2007; 19(2): 485-94.

[60] Schroeder JI, Kwak JM, Allen GJ. Guard cell abscisic acid signalling and engineering drought hardiness in plants. Nature. 2001; 410(6826): 327-30.

[61] Gosti F, Beaudoin N, Serizet C, Webb AA, Vartanian N, Giraudat J. ABI1 protein phosphatase $2 \mathrm{C}$ is a negative regulator of abscisic acid signaling. Plant Cell. 1999;11(10): 1897-910.

[62] Merlot S, Gosti F, Guerrier D, Vavasseur A, Giraudat J. The ABI1 and ABI2 protein phosphatases $2 \mathrm{C}$ act in a negative feedback regulatory loop of the abscisic acid signalling pathway. Plant J. 2001; 25(3): 295-303.

[63] Cutler S, Ghassemian M, Bonetta D, Cooney S, McCourt P. A protein farnesyl transferase involved in abscisic acid signal transduction in Arabidopsis. Science. 1996; 273(5279): 1239-41.

[64] Pei ZM, Ghassemian M, Kwak CM, McCourt P, Schroeder JI. Role of farnesyltransferase in ABA regulation of guard cell anion channels and plant water loss. Science. 1998; 282(5387): 287-90.

[65] Hugouvieux V, Kwak JM, Schroeder JI. An mRNA cap binding protein, ABH1, modulates early abscisic acid signal transduction in Arabidopsis. Cell. 2001; 106(4): 477-87.

[66] Xiong L, Gong Z, Rock CD, Subramanian S, Guo Y, Xu W, Galbraith D, Zhu JK. Modulation of abscisic acid signal transduction and biosynthesis by an Sm-like protein in Arabidopsis. Dev Cell. 2001; 1(6): 771-81.

[67] Wasternack C, Kombrink E. Jasmonates: structural requirements for lipid-derived signals active in plant stress responses and development. ACS Chem Biol. 2010; 5(1): 63-77.

[68] Fonseca S, Chico JM, Solano R. The jasmonate pathway: the ligand, the receptor and the core signalling module. Curr Opin Plant Biol. 2009; 12(5): 539-47. 
[69] Sheard LB, Tan X, Mao H, Withers J, Ben-Nissan G, Hinds TR, Kobayashi Y, Hsu FF, Sharon M, Browse J, He SY, Rizo J, Howe GA, Zheng N. Jasmonate perception by inositol-phosphate-potentiated COI1-JAZ co-receptor. Nature. 2010;468(7322): 400-5.

[70] Thines B, Katsir L, Melotto M, Niu Y, Mandaokar A, Liu G, Nomura K, He SY, Howe GA, Browse J. JAZ repressor proteins are targets of the SCF(COI1) complex during jasmonate signalling. Nature. 2007; 448(7154): 661-5.

[71] Chini A, Fonseca S, Fernández G, Adie B, Chico JM, Lorenzo O, García-Casado G, López-Vidriero I, Lozano FM, Ponce MR, Micol JL, Solano R. The JAZ family of repressors is the missing link in jasmonate signalling. Nature. 2007; 448(7154): 666-71.

[72] Fernández-Calvo P, Chini A, Fernández-Barbero G, Chico JM, Gimenez-Ibanez S, Geerinck J, Eeckhout D, Schweizer F, Godoy M, Franco-Zorrilla JM, Pauwels L, Witters E, Puga MI, Paz-Ares J, Goossens A, Reymond P, De Jaeger G, Solano R. The Arabidopsis bHLH transcription factors MYC3 and MYC4 are targets of JAZ repressors and act additively with MYC2 in the activation of jasmonate responses. Plant Cell. 2011; 23(2): 701-15.

[73] Ye H, Du H, Tang N, Li X, Xiong L. Identification and expression profiling analysis of TIFY family genes involved in stress and phytohormone responses in rice. Plant Mol Biol. 2009; 71(3): 291-305.

[74] Suhita D, Raghavendra AS, Kwak JM, Vavasseur A. Cytoplasmic alkalization precedes reactive oxygen species production during methyl jasmonate- and abscisic acid-induced stomatal closure. Plant Physiol. 2004; 134: 1536-1545.

[75] Tsonev TD, Lazova GN, Stoinova ZG, Popova LP. A possible role for jasmonic acid in adaptation of barley seedlings to salinity stress. J Plant Growth Regul. 1998; 17: 153-159.

[76] Xin L, Shi WL, Zhang SQ, Lou CH. Nitric oxide involved in signal transduction of jasmonic acid-induced stomatal closure of Vicia faba L. Chinese Sci Bull. 2005; 50: 520-525.

[77] Hossain MA, Munemasa S, Uraji M, Nakamura Y, Mori IC, Murata Y. Involvement of endogenous abscisic acid in methyl jasmonate-induced stomatal closure in Arabidopsis. Plant Physiol. 2011; 156(1): 430-8.

[78] Lackman P, González-Guzmán M, Tilleman S, Carqueijeiro I, Pérez AC, Moses T, Seo M, Kanno Y, Häkkinen ST, Van Montagu MC, Thevelein JM, Maaheimo H, OksmanCaldentey KM, Rodriguez PL, Rischer H, Goossens A. Jasmonate signaling involves the abscisic acid receptor PYL4 to regulate metabolic reprogramming in Arabidopsis and tobacco. Proc Natl Acad Sci U S A. 2011; 108(14): 5891-6.

[79] Werner T, Schmülling T. Cytokinin action in plant development. Curr Opin Plant Biol. 2009; 12(5): 527-38. 
[80] Tran LS, Shinozaki K, Yamaguchi-Shinozaki K. 2010. Role of cytokinin responsive two-component system in ABA and osmotic stress signalings. Plant Signal Behav. 5(2): 148-50.

[81] Ashikari M, Sakakibara H, Lin S, Yamamoto T, Takashi T, Nishimura A, Angeles ER, Qian Q, Kitano H, Matsuoka M. Cytokinin oxidase regulates rice grain production. Science 2005; 309: 741-745.

[82] Davies WJ, Kudoyarova G, Hartung W. Long-distance ABA signaling and its relation to other signaling pathways in the detection of soil drying and the mediation of the plant's response to drought. Journal of Plant Growth Regulation. 2005; 24: 285-295.

[83] Blackman PG, Davies WJ. Root-to-shoot communication in maize plants of the effects of soil drying. Journal of Experimental Botany 1985; 36: 39-48.

[84] Pospilisova, Jana; Batkova, P. Effects of pre-treatments with abscisic acid and/or benzyladenine on gas exchange of French bean, sugar beet, and maize leaves during water stress and after rehydration Biologia Plantarum 2004; 48 (3): 395-399.

[85] Pospíšilová, Jana; Vágner, Martin; Malbeck, Jiří; Trávníčková, Alena; Batková, Petra. Interactions between abscisic acid and cytokinins during water stress and subsequent rehydration Biologia Plantarum 2005; 49: 533-540.

[86] Mohapatra PK, Panigrahi R, Turner NC. Physiology of spikelet development on the rice panicle: is manipulation of apical dominance crucial for grain yield improvement? Advances in Agronomy. 2011; 110: 333-360.

[87] Yang J, Zhang J, Huang Z, Wang Z, Zhu Q, Liu L. Correlation of cytokinin levels in the endosperms and roots with cell number and cell division activity during endosperm development in rice. Ann Bot. 2002; 90(3): 369-77.

[88] Gleadow RM, Dalling MJ, Halloran GM. Variation in endosperm characteristics and nitrogen contents in six wheat lines. Australian Journal of Plant Physiology. 1982; 9: 539-551.

[89] Cochrane MP, Duffus CM. Endosperm cell number in barley. Nature. 1981; 289: 399401.

[90] JonesRJ, Roessler J, Quattar S. Thermal environment during endosperm cell division in maize: effects on number of endosperm cells and starch granules. Crop Science 1985; 25: 830-834.

[91] Yang J, Liu L, Wang Z, Zhu Q. Effects of flowering time of spikelets on endosperm development in rice and its physiological mechanism. Chinese Agricultural Science. 2000; 2: 70-79.

[92] Arkhipova TN, Veselov SU, Melentiev AI, Martynenko EV, Kudoyarova GR. Ability of bacterium Bacillis subtilis to produce cytokinins and to influence the growth and endogenous hormone content of lettuce plants. Plant and Soil. 2005; 272: 201-209. 
[93] Sharp RE. Interaction with ethylene: changing views on the role of abscisic acid in root and shoot growth responses to water stress. Plant, Cell and Environment. 2002; 25: 211-222.

[94] Abeles FB, Morgan PW, Saltveit ME. Ethylene in plant biology. San Diego, CA, USA: Academic Press; 1992.

[95] Rajala A, Peltonen-Sainio P. Plant growth regulator effects on spring cereal root and shoot growth. Agronomy Journal. 2001; 93: 936-943.

[96] Desikan R, Last K, Harrett-Williams R, Tagliavia C, Harter K, Hooley R, Hancock JT, Neill SJ. Ethylene-induced stomatal closure in Arabidopsis occurs via AtrbohF-mediated hydrogen peroxide synthesis. The Plant Journal. 2006; 47: 907-916.

[97] Tanaka Y, Sano T, Tamaoki M, Nakajima N, Kondo N, Hasezawa S. Ethylene inhibits abscisic acid-induced stomatal closure in Arabidopsis. Plant Physiology. 2005; 138: 2337-2343.

[98] Wilkinson S, Davies WJ. Ozone suppresses soil drying- and abscisic acid (ABA)-induced stomatal closure via an ethylene-dependent mechanism. Plant, Cell and Environment 2009; 32:949-959.

[99] Acharya BR, Assmann SM. Hormone interactions in stomatal function. Plant Molecular Biology. 2009; 69: 451-462.

[100] Zhang JZ, Creelman RA, Zhu JK: From laboratory to field. Using information from Arabidopsis to engineer salt, cold, and drought tolerance in crops. Plant Physiol 2004; 135: 615-621.

[101] Breton G, Danyluk J, Charron JB, Sarhan F. Expression profiling and bioinformatic analyses of a novel stress-regulated multispanning transmembrane protein family from cereals and Arabidopsis. Plant Physiol. 2003; 132(1): 64-74.

[102] Walia H, Wilson C, Ismail AM, Close TJ, Cui X. Comparing genomic expression patterns across plant species reveals highly diverged transcriptional dynamics in response to salt stress. BMC Genomics. 2009; 10: 398.

[103] Mangelsen E, Kilian J, Harter K, Jansson C, Wanke D, Sundberg E. Transcriptome analysis of high-temperature stress in developing barley caryopses: early stress responses and effects on storage compound biosynthesis. Mol Plant. 2010; 4(1): 97-115.

[104] Mochida K, Uehara-Yamaguchi Y, Yoshida T, Sakurai T, Shinozaki K. Global landscape of a co-expressed gene network in barley and its application to gene discovery in Triticeae crops. Plant Cell Physiol. 2011; 52(5): 785-803.

[105] Moumeni A, Satoh K, Kondoh H, Asano T, Hosaka A, Venuprasad R, Serraj R, Kumar A, Leung H, Kikuchi S. Comparative analysis of root transcriptome profiles of two pairs of drought-tolerant and susceptible rice near-isogenic lines under different drought stress. BMC Plant Biol. 2011; 11: 174. 
[106] Kausar R, Arshad M, Shahzad A, Komatsu S. Proteomics analysis of sensitive and tolerant barley genotypes under drought stress. Amino Acids; 2012. DOI: 10.1007/ s00726-012-1338-3.

[107] Lee, RC, Feinbaum, RL, Ambros, V. The C. elegans heterochronic gene lin-4 encodes small RNAs with antisense complementarity to lin-14. Cell. 1993; 75, 843-854.

[108] Axtell MJ. Evolution of microRNAs and their targets: Are all microRNAs biologically relevant? Biochim. Biophys. Acta. 2008; 1779: 725-734.

[109] Jones-Rhoades MW, Bartel DP, Bartel B. MicroRNAS and their regulatory roles in plants. Annu Rev Plant Biol 2006; 57: 19-53.

[110] Llave C, Xie Z, Kasschau KD, Carrington JC. Cleavage of Scarecrow-like mRNA targets directed by a class of Arabidopsis MiRNA. Science 2002; 297: 2053-2056.

[111] Kozomara A, Griffiths-Jones S. miRBase: integrating microRNA annotation and deep-sequencing data. NAR 2011; 39(Database Issue): D152-D157.

[112] Voinnet O. Origin, biogenesis, and activity of plant microRNAs. Cell. 2009; 136: 669687.

[113] Aukerman MJ, Sakai H. Regulation of flowering time and floral organ identity by a microRNA and its APETALA2-like target genes. The Plant Cell. 2003; 15:2730-2741.

[114] Combier JP, Frugier F, de Billy F, Boualem A, El-Yahyaoui F, Moreau S, Vernié T, Ott T, Gamas P, Crespi M, et al. MtHAP2-1 is a key transcriptional regulator of symbiotic nodule development regulated by microRNA169 in Medicago truncatula. Genes Dev. 2006; 20: 3084-3088.

[115] Palatnik JF, Allen E, Wu X, Schommer C, Schwab R, Carrington JC, Weigel D Control of leaf morphogenesis by microRNAs. Nature. 2003; 425: 257-263.

[116] Jones-Rhoades MW, Bartel DP. Computational identification of plant microRNAs and their targets, including a stress-induced miRNA. Mol. Cell. 2004; 14: 787-799.

[117] Zhou L, Liu Y, Liu Z, Kong D, Duan M, Luo L. Genome-wide identification and analysis of drought-responsive microRNAs in Oryza sativa. J Exp Bot. 2010; 61(15): 4157-68.

[118] Kulcheski FR, de Oliveira LF, Molina LG, Almerão MP, Rodrigues FA, Marcolino J, Barbosa JF, Stolf-Moreira R, Nepomuceno AL, Marcelino-Guimarães FC, Abdelnoor RV, Nascimento LC, Carazzolle MF, Pereira GA, Margis R. Identification of novel soybean microRNAs involved in abiotic and biotic stresses. BMC Genomics 2010; 12: 307.

[119] Xu C, Yang R-F, Li W-C and Fu F-L. Identification of 21 microRNAs in maize and their differential expression under drought stress. African Journal of Biotechnology. 2010; 9(30): 4741-4753. 
[120] Tuberosa R, Salvi S. Genomics approaches to improve drought tolerance in crops. Trends Plant Sci 2006; 11: 405-412.

[121] Tester M, Langridge P. Breeding technologies to increase crop production in a changing world. Science. 2010; 327: 818-822.

[122] Ludlow MM Strategies of response to water stress. Structural and Functional Responses to Environmental Stresses (eds Kreeb KH Richter H Hinckley TM). pp. 269 281. SPB Academic, The Hague. 1989.

[123] Vicre M, Farrant JM, Driouich A. Insights into the cellular mechanisms of desiccation tolerance among angiosperm resurrection plant species. Plant, Cell and Environment. 2004; 27:1329-1340.

[124] Barnabas B, Jager K, Feher A. The effect of drought and heat stress on reproductive processes in cereals. Plant, Cell and Environment. 2008; 31:11-38.

[125] Salekdeh GH, Reynolds M, Bennett J, Boyer J. Conceptual framework for drought phenotyping during molecular breeding. Trends in Plant Science. 2009; 14:488-496.

[126] Finkel E. With 'phenomics', plant scientists hope to shift breeding into overdrive. Science. 2009 ; 325: 380-381.

[127] Furbank RT. Plant phenomics: from gene to form and function. Functional Plant Biology. 2009; 36: V-VI.

[128] Ardestani H G, A Hossein, S Rad and P Zandi. Effect of Drought Stress on some Agronomic Traits of two Rapeseed varieties Grown under Different Potassium Rates. Australian Journal of Basic and Applied Sciences. 2011; 5(12): 2875-2882.

[129] Granier C, Aguirrezabal L, Chenu K, et al. PHENOPSIS, an automated platform for reproducible phenotyping of plant responses to soil water deficit in Arabidopsis thaliana permitted the identification of an accession with low sensitivity to soil water deficit. New Phytologist. 2006; 169: 623-635.

[130] Passioura JB. Grain yield, harvest index and water use of wheat. Journal of Australian Institute of Agricultural Science. 1977; 43: 117-120.

[131] Reynolds MP, Tuberosa R. Translational research impacting on crop productivity in drought-prone environmental. Curr Opin Plant Biol. 2008; 11: 171-179.

[132] Blum A. Effective use of water (EUW) and not water use efficiency (WUE) is the target of crop yield improvement under drought stress. Field Crop Res. 2009; 112: 119-123.

[133] Chaves MM, Maroco JP, Pereira JS. Understanding plant responses to drought: from genes to the whole plant. Functional Plant Biology. 2003; 30: 239-264.

[134] Flexas, J., J. Bota, F. Loreto, G. Cornic and T.D. Sharkey. Diffusive and metabolic limitation to photosynthesis under drought and salinity in C3 plants. Plant Biol. 2004; 6: 269-279. 
[135] Medrano H, Parry MAJ, Socias X, Lawlor DW. Long-term water stress inactivates Rubisco in subterranean clover. Annals of Applied Biology. 1997; 131: 491-501.

[136] David TS, Henriques MO, Kurz-Besson C, et al. Water use strategies in two co-occurring Mediterranean evergreen oaks: surviving the summer drought. Tree Physiology. 2007; 27: 793-803.

[137] Demmig-Adams, B., Ebbert, V., Mellman, D.L., Mueh, K.E., Schaffer, L., Funk, C., Zarter, C.R., Adamska, I. Jansson, S. and Adams III, W.W. Modulation of PsbS and flexible versus sustained energy dissipation by light environment in different species. Physiol. Plant. 2006; 127: 670-680.

[138] Kautsky, H. and A. Hirsch. Chlorophyllfluoreszenz und Kohlensäureassimilation. Naturwissenschaften, 1931; 19, 964.

[139] Gorbea E, Calatayud A. Applications of chlorophyll fluorescence imaging technique in horticultural research: A review. Scientia Horticulturae. 2012; 138, 1: 24-35.

[140] Kocheva K, Lambrev P, Georgiev G, Goltsev V, Karabaliev M. Evaluation of chlorophyll fluorescence and membrane injury in the leaves of barley cultivars under osmotic stress. Bioelectrochemistry. 2004; 63(1-2): 121-4.

[141] Govindjee, Srivastava, A., Strasser R.J. The "Oxygen Clock" in greening gea leaves as probed by the period four oscillations in the fluorescence intensity at 50 micro-seconds and 2milli-seconds after pre-flashing during the OJIP transient. In: Garab, G. (Ed.), Photosynthesis: Mechanisms and Effects. 1998.

[142] Yusuf, M.A., Kumar, D., Rajwanshi, R., Strasser, R.J., Tsimilli Michael, M., Govindjee, Sarin, N.B. Overexpression of $\beta$-tocopherol methyl transferase gene in transgenic Brassica juncea plants alleviates abiotic stress: physiological and chlorophyll fluorescence measurements. Biochim. Biophys. Acta. 2010; 1797: 1428-1438.

[143] Kalaji M.H., Govindjee, Bosa K., Kościelniak J., Żuk-Gołaszewska K. Effects of salt stress on photosystem II efficiency and CO2 assimilation of two Syrian barley landraces. Environmental and Experimental Botany. 2011; 73: 64-72.

[144] Pinheiro C, Chaves MM Photosynthesis and drought: can we make metabolic connections from available data? J Exp Bot 2011; 62: 869-882.

[145] Pereira JS, Chaves MM. Plant water deficits in Mediterranean ecosystems. In: Smith JAC, Griffiths H, eds. Plant responses to water deficits-from cell to community. Oxford: BIOS Scientific Publishers Ltd, 1993. 237-251.

[146] Chaves M.M., Flexas J, Pinheiro C. Photosynthesis under drought and salt stress: regulation mechanismsfrom whole plant to cell. Annals of Botany 2009; 103: 551-560.

[147] Pinheiro HA, DaMatta FM, Chaves ARM, Loureiro ME, Ducatti C. Drought tolerance is associated with rooting depth and stomatal control of water use in clones of Coffea canephora. Ann. Bot. 2005; 96:101-108. 
[148] Kirschbaum, M.U.F. Water stress in Eucalyptus pauciflora. Comparison of effects on stomatal conductance with effects on the mesophyll capacity for photosynthesis and investigation of a possible involvement of photoinhibition. Planta 1987; 171: 466-473.

[149] Ingle RA, Collett H, Cooper K, Takahashi Y, Farrant JM, Illing N. Chloroplast biogenesis during rehydration of the resurrection plant Xerophyta humilis: parallels to the etioplast-chloroplast transition. Plant Cell Environ. 2008; 31(12): 1813-24.

[150] Blum, A. and Ebercon, A. Cell membrane stability as a measure of drought and heat tolerance in wheat. Crop Science 198121 (1): 43-47.

[151] Premachandra, G.S., H. Saneoka, K. Fujita and S. Ogata. leaf water relation, osmotic adjustment, cell membrane stability, epicuticular wax load and growth as affected by increasing water deficits in sorghum. J. Exp. Bot. 1992; 43: 1569-1576.

[152] Bandurska H. Does proline accumulated in leaves of water deficit stressed barley plants confine cell membrane injury? I. Free proline accumulation and membrane injury index in drought and osmotic stressed plants. Acta Physiol. Plantarum. 2000; 22: 409-415.

[153] Sharp RE, LeNoble ME. ABA, ethylene and the control of shoot and root growth under water stress. Journal of Experimental Botany. 2002; 53: 33-37.

[154] Bengtson C., S. Larsson, C. Liljenberg. Effects of water stress on cuticular transpiration rate and amount and composition of epicuticular wax in seedlings of six oat varieties. Physiologia Plantarum 1978; 44 (4): 319-324.

[155] Islam MA, Du H, Ning J, Ye H, Xiong L. Characterization of Glossy1-homologous genes in rice involved in leaf wax accumulation and drought resistance. Plant Mol Biol. 2009; 70(4): 443-56.

[156] Jordan WR, Shouse PJ, Blum A, Miller FR, Monk RL. Environmental physiology of sorghum. II. Epicuticular wax load and cuticular transpiration. Crop Sci 1984; 24: 168-173.

[157] Jefferson P.G., D.A. Johanson, M.D. Runbaugh, K.H. Asay. Water stress and genotypic effects on epicuticular wax production of alfalfa and crested wheat grass in relation to yield and excised leaf water loss rate. Can. J. Plant Sci., 1989; 69: 481-490.

[158] Yang J, Isabel Ordiz M, Jaworski JG, Beachy RN. Induced accumulation of cuticular waxes enhances drought tolerance in Arabidopsis by changes in development of stomata. Plant Physiol Biochem. 2011; 49(12): 1448-55.

[159] Jackson RD, Idso SB, Reginato RJ, Pinter PJ. Canopy temperature as a crop waterstress indicator. Water Resources Research 1981; 17: 1133-1138.

[160] Jones HG, Stoll M, Santos T, de Sousa C, Chaves MM, Grant OM. Use of infrared thermography for monitoring stomatal closure in the field: application to grapevine. Journal of Experimental Botany 2002; 53: 2249-2260. 
[161] Jones HG, Serraj R, Loveys BR, Xiong LZ, Wheaton A, Price AH. Thermal infrared imaging of crop canopies for the remote diagnosis and quantification of plant responses to water stress in the field. Functional Plant Biology 2009; 36: 978-989.

[162] Martin B, Ruiztorres NA. Effects of water-deficit stress on photosynthesis, its components and component limitations, and on water-use efficiency in wheat (Triticum aestivum L). Plant Physiology 1992; 100: 733-739.

[163] Medrano H, Escalona JM, Bota J, Gulias J, Flexas J. Regulation of photosynthesis of C3 plants in response to progressive drought: Stomatal conductance as a reference parameter. Ann. Bot. 2002; 89: 895-905.

[164] Umezawa T, Fujita M, Fujita Y, Yamaguchi-Shinozaki K, Shinozaki K. Engineering drought tolerance in plants: discovering and tailoring genes unlock the future. Current Opinion in Biotechnology 2006; 17: 113-122.

[165] Yang S, Vanderbeld B, Wan J, Huang Y. 2010. Narrowing down the targets: towards successful genetic engineering of drought-tolerant crops. Mol Plant. 3(3): 469-90.

[166] Century K, Reuber TL, Ratcliffe OJ. Regulating the regulators: the future prospects for transcription-factor-based agricultural biotechnology products. Plant Physiol. 2008; 147(1): 20-9.

[167] Du H, Wang N, Cui F, Li X, Xiao J, Xiong L. Characterization of the beta-carotene hydroxylase gene DSM2 conferring drought and oxidative stress resistance by increasing xanthophylls and abscisic acid synthesis in rice. Plant Physiol. 2010; 154(3): 1304-18.

[168] Huang XY, Chao DY, Gao JP, Zhu MZ, Shi M, Lin HX. A previously unknown zinc finger protein, DST, regulates drought and salt tolerance in rice via stomatal aperture control. Genes Dev. 2009; 23(15): 1805-17.

[169] Zhang SW, Li CH, Cao J, Zhang YC, Zhang SQ, Xia YF, Sun DY, Sun Y. Altered architecture and enhanced drought tolerance in rice via the down-regulation of indole-3-acetic acid by TLD1/OsGH3.13 activation. Plant Physiol. 2009; 151(4): 1889-901.

[170] Castiglioni P, Warner D, Bensen RJ, Anstrom DC, Harrison J, Stoecker M, Abad M, Kumar G, Salvador S, D'Ordine R, Navarro S, Back S, Fernandes M, Targolli J, Dasgupta S, Bonin C, Luethy MH, Heard JE. Bacterial RNA chaperones confer abiotic stress tolerance in plants and improved grain yield in maize under water-limited conditions. Plant Physiol. 2008; 147(2): 446-55.

[171] Deikman J, Petracek M, Heard JE. Drought tolerance through biotechnology: improving translation from the laboratory to farmers' fields. Curr Opin Biotechnol. 2012; 23(2): 243-50.

[172] Kerrien S, Aranda B, Breuza L, Bridge A, Broackes-Carter F, Chen C, Duesbury M, Dumousseau M, Feuermann M, Hinz U, Jandrasits C, Jimenez RC, Khadake J, Maha- 
devan U, Masson P, Pedruzzi I, Pfeiffenberger E, Porras P, Raghunath A, Roechert B, Orchard S, Hermjakob H. The IntAct molecular interaction database in 2012. Nucleic Acids Res. 2012; 40(Database issue): D841-6.

[173] Stark C, Breitkreutz BJ, Chatr-Aryamontri A, Boucher L, Oughtred R, Livstone MS, Nixon J, Van Auken K, Wang X, Shi X, Reguly T, Rust JM, Winter A, Dolinski K, Tyers M. The BioGRID Interaction Database: 2011 update. Nucleic Acids Res. 2011; 39(Database issue): D698-704. 
